\title{
UNCONTROLLED COUNTER-KNOWLEDGE: ITS EFFECTS ON KNOWLEDGE MANAGEMENT CORRIDORS
}

\begin{abstract}
Disinformation and misconceptions based on unverified information (e.g., hoaxes, exaggerations or gossip) is what is called "counter-knowledge". Knowledge management corridors establish a framework for relationships between the external and internal knowledge processes to enhance organizational performance. This study proposes three knowledge management processes (i.e., realized absorptive capacity, organizational memory, and knowledge application) as those that constitute such critical corridors. The analysis of the role of uncontrolled counter-knowledge in the relationship between those knowledge management processes is the value of this paper. Hypotheses were tested using a SEM approach based on composites (PLS-SEM). Data were collected from 151 branch-office managers belonging to the Spanish banking industry. The results show that counter-knowledge is only related to realized absorptive capacity and knowledge application, being the influence negative. The link between counterknowledge and the other two constructs (i.e., organizational memory and organizational performance) provides surprising results being statistically insignificant.
\end{abstract}

Keywords - Knowledge management processes, Counter-knowledge, Performance, Realized absorptive capacity, PLS

Paper type - Academic Research Paper 


\section{Introduction}

Knowledge is recognized as a key resource for firms in the current business environment. Nevertheless, many of the knowledge processes that exist today are based on gossip, partial truth and hoaxes. The use of the unverified information of the Internet and other media such as TV or radio causes people to be exposed to a vast amount of lies and exaggerations (Kurland \& Pelled, 2000). The misinformation and misconceptions packaged to look like "fact" and obtained from unverified sources of information is what in this paper has been termed "counter-knowledge" (Thompson, 2008).

Firms need to have a set of resources to create, share, and use knowledge (Chou et al, 2007; Lin, 2007; among others). In this vein, organizations should have processes for sharing knowledge (i.e., organizational memory) and for using the knowledge created (i.e., knowledge application) in order to support the management of knowledge to increase their performance. Given the importance of external knowledge for the development and increase in employees' knowledge (Newey \& Zahra, 2009), realized absorptive capacity also represents an important part of a firm's ability to create new knowledge (Lane et al, 2006; Liao et al, 2010). It is the start of what is called a "knowledge management (KM) corridor".

A corridor can be defined as a passage connecting parts of a building. A KM corridor connects one inlet of the knowledge process to another outlet port and opens the exhaust to other knowledge structures (Martelo-Landroguez \& Cegarra, 2014). In this study, a KM corridor establishes a framework for relations between the external and internal knowledge processes to enhance organizational performance. According to the existing literature, this study proposes the following KM processes as those that constitute a KM corridor to connect external knowledge to firm performance: realized absorptive capacity (RACAP), organizational memory (OM), and knowledge application (KA).

It should be noted here that counter-knowledge can be seen as a natural deterioration or depreciation of organizational knowledge, usually with negative consequences for customers (Cegarra et al, 2012). Regarding this, uncontrolled counter-knowledge can hinder learning at individual and organizational levels (Cegarra et al, 2014), which in turn can obstruct the implementation of comprehensive and integrated policies (Cegarra et al, 2015). Although counter-knowledge can have major negative impacts on both 
external and internal knowledge processes, very little has been written up to now about the role played by uncontrolled counter-knowledge in the different KM processes.

This paper tries to find what the direct effect of counter-knowledge on the KM processes is and its possible impact on firm performance. In this study, the following research questions are addressed: Is bad for a KM corridor to have access to counterknowledge? Does the presence of counter-knowledge hinder the relationship between KM processes and performance? This study uses the structural equation modelling (SEM) approach to test the research hypotheses. The model was assessed using a sample of 151 branch-office managers who belonged to the 15 banks operating in Spain in 2013. In the following sections, the concepts discussed above are examined in greater detail and the potential relationships between them are explored.

\section{Theoretical background}

Counter-knowledge is a new concept that emerged at the turn of this century. Although the term was initially associated with the production and circulation of conspiracy theories (Thompson, 2008; Gosa, 2011), Cegarra et al (2012) extrapolated this concept to the presence of obsolete knowledge structures. However, further studies have determined that counter-knowledge derives from sources of unverified information (i.e., hoaxes, exaggerations, and gossip) rather than outdated processes or routines (Cegarra et al, 2014, 2015).

A possible explanation for the discrepancy between above definitions may relate to the fact that counter-knowledge and outdated knowledge can be related to the different concepts of "clearance" and "erasure" introduced by Bowker (1997). While "clearance" relates to the total wiping away of misinformation packaged to look like "fact" by constructing a blockade that prevents wrong counter-knowledge from flowing to the present, "erasure" describes the constant identification of outdated knowledge not worth using at a specific time (Bowker, 1997). This means that while outdated knowledge might be especially useful in one context, it might not be in another. However, counterknowledge in itself is an important barrier to learning (e.g., misinformation or misconceptions).

Firms that are able to manage knowledge have a competitive advantage (Moustaghfir, 2009). For this reason, managers are increasingly aware that KM processes are 
necessary to their firm's development and sustainability (Carneiro, 2000; Schiuma, 2009; Lee et al, 2013). Hence, the key challenge is to find the KM processes that make knowledge consistent and useful in order to achieve the objectives of the firm.

Despite many attempts to identify the different KM processes, a review of the existing literature reveals some disagreement over the number and labeling of such processes. Nevertheless, there are many authors who agree in proposing three fundamental KM processes: one related to the creation of knowledge, another related to the sharing of knowledge, and another related to its use (Gold et al, 2001; Chou et al, 2007; Huang \& Li, 2009; Wee \& Chua, 2013). According to such previous studies, as said before, this paper focuses on RACAP, OM, and KA as the main KM processes required to increase firm performance.

In following the above steps ( $\mathrm{RACAP} \rightarrow \mathrm{OM} \rightarrow \mathrm{KA}$ ), employees can take advantage of creating new knowledge, and capturing and using the knowledge that already exists in the firm in order to perform competitive tasks. In this paper, the alignment between RACAP, OM, KA and organizational performance has been called a "KM corridor". This is due to the fact that these processes connect to each other across the organization, aligning them not only with the people who work in the firm (OM, and KA), but most decisively, with customer priorities as well (RACAP). With this in mind, these processes may form part of a broader strategy promoted by the organization, seeking to improve the effectiveness (Martelo-Landroguez \& Cegarra, 2014).

Realized absorptive capacity (RACAP) refers to the search of relevant knowledge or the addition of new one into firm operations. Organizational memory $(\mathrm{OM})$ is considered to be the collective recollection of experience, meanings applied to experience and inferences of meaning (Moorman \& Miner, 1998). And knowledge application (KA) refers to the way firms apply learned knowledge to new understandings and situations in order to create the perception among their customers that their version of product/service is somehow different from the competition and, therefore, it has added value that is not available from competitors (Alavi \& Leidner, 2001).

If firms want to improve their performance, employees not only need to obtain and use the existing knowledge in firms but also they need to create new knowledge. Several studies propose that the ability to exploit effectively external knowledge is a critical factor for companies (Grandinetti, 2016). This is the reason why this paper includes the 
realized absorptive capacity (RACAP) in the analysis. In this paper, RACAP refers to that leverage of the acquired external knowledge (Martelo-Landroguez \& Cepeda, 2016).

Additionally, organizational memory refers to the processing of saved knowledge. Walsh \& Ungson (1991, p. 61) define organizational memory as "the stored information from an organization's history that can be brought to bear on present decisions". The aim is to make knowledge available to the employees who need it. In order to obtain knowledge that could be useful in their work and that could help them in decisionmaking processes, it is paramount that employees have access to knowledge base. Firms' accumulated knowledge can also play a key role in removing obstacles and inefficiencies and, at the same time, in improving organizational performance (Walsh \& Ungson, 1991). This is the reason why firms must retain systematically the knowledge created if they want to be able to use it for the benefit of future organizational operations (Chang Lee et al, 2005). Thus, organizational memory gives firms access to the knowledge retained over time.

Some benefits of organizational memory in firms are (Stein, 1995): (1) maintain the strategic direction of the firm over time; (2) avoid the nightmare of having to search among old solutions to solve new problems because no one can remember what was done before; (3) give new meaning to people's work if their efforts are retained; (4) facilitate organizational learning; (5) strengthen the identity of the company; and (6) give newcomers access to the experience of those who precede them. Thus, organizational memory is considered as the way knowledge is stored in different places in a firm.

But firms also need to use their knowledge to support and enhance business operations. Therefore, knowledge application is considered as the actual use of knowledge in firms. The application of knowledge allows firms to learn from mistakes, solve problems, improve efficiency and deal with changing competitive needs (Gold et al, 2001). The use that employees make of knowledge will depend on the availability of knowledge stored in firms and the degree to which employees actively access this knowledge and integrate it into their general knowledge of the situation and their preferences (Chou et al, 2007).

\section{Research model}


Findings about the presence of counter-knowledge have been mixed in the existing literature. While some authors have reported that counter-knowledge may be useful for social influence or for entertainment (Yerkovich, 1977; Ben-Ze'ev, 1994; Baumgartner et al, 2014), other authors maintain that counter-knowledge hinders the ability of individuals to plan and engage in advocacy activities (Cegarra et al, 2014, 2015). A possible explanation for these contradictory results would be the fact that prior research has indicated that counter-knowledge generated via unverified sources of information may be partially controlled (e.g., Cegarra et al, 2014, 2015). In this study, counterknowledge has been directly linked to the relationship between KM processes and performance (i.e., what is called a KM corridor). Therefore, this research maintains a negative stance on counter-knowledge, particularly when it cannot be controlled and it hinders individuals' ability to reason and understand knowledge effectively.

Although there has been discussion in recent literature about the relationship between the three proposed KM processes (Lee et al, 2013); between knowledge application and performance (Martelo-Landroguez \& Martin-Ruiz, 2016); and between other KM processes and firm performance (Chen et al, 2010; Inkinen, 2016); there is no research that has taken into consideration the effect of counter-knowledge on these relationships. This paper proposes that the existence of counter-knowledge in firms will influence their KM processes. It is also proposed that counter-knowledge will have an impact on firms' performance. That is to say, counter-knowledge could influence KM processes and firm performance (i.e., KM corridors) owing to managers and employees perceive and follow knowledge structures that arise from rumors and outdated routines and procedures (Cegarra et al, 2015).

It seems clear that external controlled knowledge is different from external uncontrolled knowledge, because the former carries out a verification of the sources of information, whereas the latter does really tally information from unverified contradictory sources (Ronstadt, 1988; Martelo-Landroguez \& Cegarra, 2014; Cegarra-Sanchez et al, 2017). Advocates of absorptive capacity alike agree that many organizations face dynamic environments where successful performance depends on their ability to respond to rapidly changing knowledge (Liao et al, 2004; Greenhill \& Oppenheim, 2017). Regarding external controlled knowledge, this study adopts this approach and relates realized absorptive capacity to emerging literature on the links between the $\mathrm{KM}$ processes at the organizational level (i.e., OM and KA) to then propose a conceptual 
framework which proposes three lineal cause/effect relationships to facilitate organizational performance (Ronstadt, 1988; Husted \& De Jesus Salazar, 2006; Martelo-Landroguez \& Cegarra, 2014; Cegarra-Sanchez et al, 2017). It is explained below how to augment organizational performance and facilitate the interaction between the different $\mathrm{KM}$ processes.

Firstly, firms must focus on knowledge creation. It is important for firms to develop an absorptive capacity because it refers to the ability to use prior knowledge to recognize the value of new information, assimilate it and apply it to create new knowledge and capabilities (Cohen \& Levinthal, 1990). That is, firms need to leverage the external knowledge that has been absorbed (i.e., RACAP). Thus, the following hypothesis is proposed:

Hypothesis 1: Realized absorptive capacity is positively related to Organizational memory.

Then, knowledge that people obtain from their experience in the firm must be retained in order to avoid repeating past mistakes, to ensure the continuous use of best practices, and to leverage the past and present collective wisdom of their employees (Kransdorff \& Williams, 2000; Nilakanta et al, 2006). Therefore, if a firm retains the knowledge created over time, the next step must be the use of this stored knowledge to support business operations. Thus, the following hypothesis is proposed:

Hypothesis 2: Organizational memory is positively related to Knowledge application.

The relationship between the application of knowledge and organizational performance is important to make sure that the existing knowledge is applied appropriately to increase performance. Managers are interested in managing knowledge but not for the sake of knowledge management. The interest of managers in the management of knowledge is due to it can support the improvement of firm performance (Schiuma, 2012). Thus, the following hypothesis is proposed:

Hypothesis 3: Knowledge application is positively related to Organizational performance.

Regarding external uncontrolled knowledge, the research is ambiguous. On the one hand, prior research has found that counter-knowledge can lead to a better social 
integration (Yerkovich, 1977; Baumeister et al, 2004), which in turn may help employees to interpret ambiguous situations (Schaefer, 2005). However, other studies have found that counter-knowledge can provoke doubts about the efficacy and appropriateness of some goals regarding organizational instructions (Cegarra et al, 2016), which in turn could be used by employees to misunderstand what they can truly achieve with their programs and routines (Chapman \& Ferfolja, 2001).

In line with the above-mentioned thinking, Cegarra et al (2016) reported very confusing results about counter-knowledge. They found that counter-knowledge is a variable that, when controlled, has the effect of strengthening the relationship between two variables. However, early work by Cegarra et al (2014) proposed a framework for examining the uncontrolled link between counter-knowledge and RACAP. The framework placed its emphasis on how uncontrolled counter-knowledge may be considered a source for the deterioration of the proposed KM processes and firm's performance (i.e., what is called "KM corridor") as a result of: 1) narrowing the cognitive process of individuals; 2) hindering their ability to plan, reason, and understand the situation effectively; 3) fostering a sense of inadequacy with regard to the combination of unexpected links between variables, such as people and processes; and 4) limiting individuals' prior knowledge of the potential interactions between new processes and their consequences.

In the emerging literature related to counter-knowledge a substantial amount of theorising has been presented dealing with the combination of unverified external information and $\mathrm{KM}$ processes relating to organizational performance (e.g., Cegarra $e t$ al, 2012, 2014, 2015; Cegarra-Sanchez et al, 2017). This paper further develops some of these ideas, and it contributes to better understand how "uncontrolled counterknowledge" can deteriorate the KM corridor described above (see Figure 1) through bringing together different programs and routines. Therefore, the following hypotheses are proposed:

Hypothesis 4: Realized absorptive capacity is influenced negatively by counterknowledge.

Hypothesis 5: Organizational memory is influenced negatively by counter-knowledge.

Hypothesis 6: Knowledge application is influenced negatively by counter-knowledge. 
Hypothesis 7: Organizational performance is influenced negatively by counterknowledge.

\author{
Insert Figure 1 about here
}

\title{
Methodology
}

\section{Data Collection}

Since 2008, the Spanish banking industry is undergoing a major restructuring due to a financial crisis. Banks and saving banks have undergone several mergers and acquisitions (e.g., most savings banks have become banks today). The instability in jobs in this industry, which is caused by these changes, constitutes one of the main reasons for choosing this research context. The above-mentioned changes have led to the reduction in the number of branches, employees, and structure costs. These reductions are taking place gradually in time. As a result, employees are nervous and continuous rumors about new dismissals waves arise, without knowing if the information is real or just lies, exaggerations, or partial truths. The turbulence in the banking industry and the continuous changing environment also causes the need to control the rumors so that it does not affect KM corridors.

Another reason is the way of working in banks. Two or more individuals often work together with different resources and information. The employees in each branch office are continuously in contact with customers, but each one attends to certain customers. Then, such amount of information and knowledge about customers is transferred throughout the organization, and used in decision-making. Consequently, the Spanish banking industry constitutes a suitable context to test empirically the proposed hypotheses because banking activities demonstrate KM capabilities, and rumors and misinformation have become the norm in this industry.

The unit of analysis is branch-office managers from the 15 banks operating in Spain in 2013. Data were collected over a period of two months, from September 2013 to November 2013. 307 branch-office managers received telephone and mailing invitations to participate in the study. A total of 153 questionnaires were completed. Two of these 
questionnaires were unsatisfactory. Hence, the analysis is based on responses from 151 valid questionnaires $(49.18 \%$ response rate).

\section{Measures}

Four items made up the scale for counter-knowledge (Cegarra et al, 2015). That scale reflects an accurate picture of the idea of counter-knowledge of the current research (i.e., wrong knowledge learnt from sources of unverified information). An absorptive capacity scale proposed by Jansen et al (2005) has been used to measure knowledge creation, which adds to the conceptual richness of the study. This scale consists of 12 items to measure RACAP.

In the case of organizational memory, this study used Chou et al's (2007) scale which consists of four items. Gold et al's (2001) scale was used to measure the application of knowledge. This scale consists of 12 items. After cleaning the data, KA scale includes 10 items.

A scale to measure organizational performance has been adapted. The scale used, adapted from Quinn \& Rohrbaugh (1983), consisted of 12 items. Prior studies have shown that perceived measures of performance can be a reasonable substitute for objective measures of financial performance and have a significant correlation with them (e.g., Venkatraman \& Ramanujam, 1987; Geringer \& Hebert, 1989).

This study used a survey to collect data on a 7-point Likert scale. Following Henseler (2017), the latent variables were measured as composites because all former measures were making up of their indicators or measures. Furthermore, all constructs were considered Mode A composites.

\section{Data Analysis}

The proposed hypotheses were tested simultaneously using partial least squares (PLSSEM) (Richter et al, 2016). All measures were considered as composites, then PLSSEM is the most suitable data analysis technique to test this kind of models. It implies that the total variance of all constructs is used to estimate model parameters (Hair et al, 
2017). Any PLS-SEM requires specific attention with regard to model identification (Henseler et al, 2016), such that each construct needs a nomological net in order to be assessed. The conceptual model identification is most appropriate if there is a strong theory and there are previous empirical studies with sound evidence. The purpose of this PLS-SEM analysis was explanatory (i.e., test the proposed hypotheses and maximize the variance of the dependent construct) and confirmatory (i.e., fit indices was shown).

Data analysis follows different stages according to the recent advances of PLS-SEM reporting (Henseler et al, 2016; Hair et al, 2017) and the recent call for PLS-SEM emancipation due to the different epistemological nature of the measures (common factor versus composites) (Rigdon, 2016). Firstly, the model fit was analyzed. The standardized root mean square residual (SRMR) constitutes a measure of approximate fit as it can help quantify the degree of (mis-)fit (Henseler et al, 2014). The SRMR of well-fitting models typically does not exceed a value of 0.08 (Henseler et al, 2016) and is acceptable to PLS-SEM (Hair et al, 2017).

Once the model fit is established, the assessment of the measurement model was carried out. The confirmatory composite analysis is a recent global measure of it. It was performed by analyzing the fit model of the saturated model (Henseler et al, 2016; Henseler, 2017). To demonstrate sufficient reliability and validity of the model composites, the most appropriate consistent measure of internal consistency reliability is $\rho_{\mathrm{A}}$ and consistent reliability (Henseler et al, 2016). While reliability values as low as 0.7 indicate proper reliability in the early phases of research, higher values such as 0.8 or 0.9 should be used in more advanced research (Nunnally, 1978), which exceed the common threshold values. The average variance extracted (AVE) serves as a measure of unidimensionality and should be bigger than 0.5 (Fornell \& Larcker, 1981). Finally, a heterotrait-monotrait ratio of correlations (HTMT) that is clearly below 1 provides evidence of discriminant validity (Henseler et al, 2015).

Finally, the so-called structural model was assessed. Now the hypothesized relationships between composites was analyzed. The most important result of the structural model are the path coefficients and dependent construct $\mathrm{R}^{2}$. They indicate that the change in a dependent variable is a consequence of a unit change in an independent variable if all other independent variables remain constant. Bootstrap percentile 
confidence intervals of the path coefficients help in the generalization from the sample to the population. The consideration of bootstrap percentile confidence intervals gives greater assurance than simply relying on null hypothesis significance testing (Cohen, 1994). This study used the SmartPLS v. 3.2.7 to run PLS-SEM (Ringle et al, 2015).

\section{Results}

The proposed model has a good fit. The SRMR value for the estimated model is 0.068 . As it has been already commented, there are two phases in the analysis and interpretation of the PLS-SEM estimations: (1) the assessment of the reliability and validity of the outer model (i.e., measurement model); and (2) the examination of the inner model (i.e., structural model).

\section{Outer Model}

The results show that the outer model meets all commonly stipulated requirements. First, the SRMR of the saturated model is reported as a measure of the quality of the measurement model as it does not exceed the value of 0.08 (Henseler et al, 2016). The SRMR for the saturated model was 0.066 .

Second, individual items are reliable since all standardized loadings are greater than 0.7 , except one indicator of the performance composite that was a little below that value but was retained. Third, the model satisfies the prerequisite of construct reliability because all Dijkstra and Henseler's $\rho$ are greater than 0.8 (Table 1). Furthermore, the scores for the average variance extracted (AVE) surpass the threshold of 0.5 (Table 1) for composites' unidimensionality, and these latent variables therefore achieve convergent validity. Finally, all the variables attain discriminant validity, since all HTMT are below 0.85 (Table 1).

Insert Table 1 about here

Inner Model 
Hayes \& Scharkow (2013) showed that the bootstrap confidence interval is a good approach for detecting path coefficients. All the path coefficients in Table 2 are supported, with two exceptions: H5 (counter-knowledge on organizational memory) and H7 (counter-knowledge on performance). The percentile bootstraps at $95 \%$ confidence intervals have this outcome (Table 2). The proposed model explains the 64.5 percent of the variance in performance $\left(\mathrm{R}^{2}\right)$. Together, from the above analysis, hypotheses $1,2,3$, 4 and 6 found support. Additional, we did not find collinearity issues in exogenous construct.

Insert Table 2 about here 


\section{Discussion}

Memories are rarely complete or accurate descriptions or interpretations of history. In fact, in the same way that someone may have both good and bad memories, organizational memory may provide workers with room to share both good and bad knowledge (e.g., false histories or wrong oriented targets). Social interactions inside and beyond departments constitute a constructivist context to share misinformation and misconceptions packaged to look like "fact", whereby knowledge is not only "discovered" but is also socially constructed. Therefore, all so-called "knowledge" generated through social interactions is not necessarily good knowledge; but counterknowledge as well.

This study provides insight into the influence of $\mathrm{KM}$ processes on organizational performance. The results confirm that RACAP impacts positively on OM, and that it relates positively to KA which, in turn, increases organizational performance. This is in broad agreement with the conclusions of authors such as Cegarra-Sanchez et al (2017), Martelo-Landroguez \& Cegarra (2014) and Ronstadt (1988), who assert that organizational performance may suffer shorter-term positive or negative influences from knowledge corridors ( $\mathrm{RACAP} \rightarrow \mathrm{OM} \rightarrow \mathrm{KA}$ ). As mentioned before, previous studies analyse the association between KM processes and performance. Nevertheless, this study includes counter-knowledge in that analysis. This study also find evidences for the role of counter-knowledge on the former constructs. Concretely, it finds support to the negative influence of counter-knowledge on two of the proposed KM processes (i.e., RACAP and KA).

The above findings confirm that knowledge built on the existing uncontrolled counterknowledge may be negatively affected by unreliable claims, false assumptions, rumors or gossip, as initially argued by Cegarra et al (2014, 2015). Despite the fact that uncontrolled counter-knowledge is an important cause for the destabilization of KM processes as it contributes to misunderstandings or wrong assumptions, results from previous studies do not provide conclusive evidence for either the benefits or harms of counter-knowledge. While there are authors who argue that counter-knowledge may be useful for transferring information to others, for social influence, and for entertainment (e.g., Yerkovich, 1977; Baumeister et al, 2004), others suggest that counter-knowledge potentially leads to a degradation of knowledge (Chapman \& Ferfolja, 2001). The 
results of this research are in line with these inconsistent findings (e.g., Sánchez-Casado et al, 2015; Cegarra-Sanchez et al, 2017). This means that, although this study found that the presence of counter-knowledge hinders the KA and RACAP, it did not find a significant relationship between either OM or performance and counter-knowledge.

This study contributes to the academic debate on how best to restrict access to uncontrolled counter-knowledge. Findings support that counter-knowledge negatively influences knowledge application and RACAP. A possible explanation for this finding may relate to the fact that through the application of knowledge, finance employees cannot discern between the verified information and the unverified information (Liao et al, 2004). Another possible explanation for this might be that when finance employees apply knowledge processes to solve problems, rather than engaging in a careful research of verified information across the branch, they first investigate unverified information such as false assumptions, rumors or gossip with respect to services or processes (Greenhill \& Oppenheim, 2017). Under this framework, it is likely that finance employees are more prone to rumors and gossip at the moment when the knowledge is acquired and applied rather than, for example, on storing or harvesting the knowledge (Liao et al, 2004; Greenhill \& Oppenheim, 2017). When this happens, unchannelled and uncontrolled rumors, gossip or lies (i.e., counter-knowledge) may lead to misunderstandings, disagreements or loss of trust and a downward spiral into the company's memory (Cegarra et al, 2014, 2015).

The link associated with counter-knowledge and OM provides somewhat surprising results being statistically insignificant. This contradicts the belief in the literature that counter-knowledge potentially leads to a degradation of knowledge (Chapman \& Ferfolja, 2001). It should be noted here that we easily remember the good things we liked about the past and conveniently forget the parts of the past that we did not like (e.g., bad effects of gossip). In other words, it seems that when people store knowledge as processes, protocols or routines they make their own judgment about what is right and what is unverified information. For example, when you have to rely on someone else to ask him/her something, you would avoid someone who spreads gossip about you or someone else very close to you. Therefore, OM may increase the capacity to understand counter-knowledge based on unverified information, which in turn may make finance employees to avoid counter-knowledge as gossip and rumors. 
This paper's second contribution stresses that "spreading unverified information" is one thing and "taking this information seriously" another. The results show an insignificant relationship between counter-knowledge and organizational performance, which means that counter-knowledge is unlikely to affect the banks directly. This confirms the position adopted by Husted \& De Jesus Salazar (2006) when they argued that greater organizational performance will be achieved by the strategic approach, rather than by the altruistic approach. A possible explanation of this finding would be the fact that although everybody has reasons to spread unverified information (e.g., when there is uncertainty or one feels anxiety) in a cheerful and contemporary atmosphere, after a while we do not take seriously this unverified information. In fact, we do not live in a perfect world. For instance, our team mates, partners or even the manager of our branch may give us reasons to consider murder. But one thing is to have a fantasy, quite another is to spend time and resources planning how to kill our boss. If this idea is extrapolated to organizational development issues such as quality services or productivity, it can be asserted that although employees are exposed to a vast amount of lies and exaggerations, they do not allow this information affects their daily work decisions.

\section{Conclusions}

This paper aims to examine the counter-knowledge's influence on KM corridors using data of 151 branch-office managers from the Spanish banking industry. KM processes and performance are found to be positively and significantly related. It highlights the importance of the proposed $\mathrm{KM}$ processes in ensuring the improvement of organizational performance. Findings also show that counter-knowledge is only related to realized absorptive capacity and knowledge application, being the influence negative. To sum up, the study contributes to the literature by empirically testing the impact of counter-knowledge on the relationship between KM processes and performance (i.e., what is called "KM corridor").

This study has several limitations that have to be pointed out. The study has only taken a snapshot and it would be interesting to observe the change in the KM corridor via time through the gathering and analysis of longitudinal data sets. It should also be noted here that, despite the fact that measures have been defined as precisely as possible, constructs are very difficult to quantify. Further research through interviews and observational case 
studies could be undertaken to triangulate. Although the study provides examples to support that counter-knowledge exists among finance employees and that it causes problems for the acquisition and application of knowledge; it must be clear that it is not the goal of this study to analyze intentionality of counter-knowledge. In addition, even though counter-knowledge refers to knowledge learnt from unverified information, the interpretation of unverified information is to some extent inevitably subjective. This means that the degree of intentionality and subjectivity of counter-knowledge should be reviewed and explored further since the deliberate misleading of people is an interesting subject for future discussion. 


\section{References}

Alavi M and Leidner DE (2001) Review: knowledge management and knowledge management systems: conceptual foundations and research issues. MIS Quarterly 25(1), 107-136.

Baumeister RF, Zhang L and Vohs KD (2004) Gossip as cultural learning. Review of General Psychology 8(2), 111-121.

Baumgartner SE, Weeda WD, van der Heijden LL and Huizinga M (2014) The relationship between media multitasking and executive function in early adolescents. The Journal of Early Adolescence 34(8), 1120-1144.

Ben-Ze'ev A (1994) The vindication of gossip. In Good Gossip (Goodman RF and BenZe'ev A, Eds), pp 11-24, University Press of Kansas, Lawrence, KS, US.

Bowker GC (1997) Lest we remember: Organizational forgetting and the production of knowledge. Accounting, Management and Information Technologies 7(3), 113-138.

Carneiro A (2000) How does knowledge management influence innovation and competitiveness? Journal of Knowledge Management 4(2), 87-98.

Cegarra JG, Cepeda G and Wensley A (2015) Negative aspects of counter-knowledge on absorptive capacity and human capital. Journal of Intellectual Capital 16(4), 763-778.

Cegarra JG, Eldridge S and Gamo A (2012) How an unlearning context can help managers overcome the negative effects of counter-knowledge. Journal of Management \& Organization 18(2), 231-246.

Cegarra JG, Eldridge S and Wensley A (2014) Counter-knowledge and realized absorptive capacity. European Management Journal 32(2), 165-176.

Cegarra JG, Wensley A, Garcia-Perez A and Sotos-Villarejo A (2016) Linking peripheral vision with relational capital through knowledge structures. Journal of Intellectual Capital 17(4), 714-733. 
Cegarra-Sanchez J, Cegarra JG, Wensley A and Diaz-Manzano J (2017) Overcoming counter-knowledge through telemedicine communication technologies. Journal of Health Organization and Management 31(7/8), 730-745.

Chang Lee K, Lee S and Kang IW (2005) KMPI: measuring knowledge management performance. Information \& Management 42(3), 469-482.

Chapman JA and Ferfolja T (2001) The acquisition of imperfect mental models and their use in hazardous situations. Journal of Intellectual Capital 2(4), 398-409.

Chen CJ, Huang JW and Hsiao YC (2010) Knowledge management and innovativeness: the role of organizational climate and structure. International Journal of Manpower 31(8), 848-870.

Chou T-C, Chang P-L, Cheng Y-P and Tsai C-T (2007) A path model linking organizational knowledge attributes, information processing capabilities, and perceived usability. Information \& Management 44(4), 408-417.

Cohen J (1994) The earth is round ( $\mathrm{p}<.05)$. American Psychologist 49(12), 997-1003.

Cohen WM and Levinthal DA (1990) Absorptive capacity: a new perspective on learning and innovation. Administrative Science Quarterly 35(1), 128-152.

Fornell C and Larcker DF (1981) Evaluating structural equation models with unobservable variables and measurement error. Journal of Marketing Research 18(1), 39-50.

Geringer JM and Hebert L (1989) Control and performance of international joint ventures. Journal of International Business Studies 20(2), 235-254.

Gold AH, Malhotra A and Segars AH (2001) Knowledge management: an organizational capabilities perspective. Journal of Management Information Systems $18(1), 185-214$.

Gosa TL (2011) Counterknowledge, racial paranoia, and the cultic milieu: decoding hip hop conspiracy theory. Poetics 39(3), 187-204.

Grandinetti R (2016) Absorptive capacity and knowledge management in small and medium enterprises. Knowledge Management Research \& Practice 14(2), 159-168. 
Greenhill KM and Oppenheim B (2017) Rumor has it: the adoption of unverified information in conflict zones. International Studies Quarterly 61(3), 660-676.

Hair JF, Hult GTM, Ringle CM, Sarstedt M and Thiele KO (2017) Mirror, mirror on the wall: a comparative evaluation of composite-based structural equation modeling methods. Journal of the Academy of Marketing Science 45(5), 616-632.

Hayes AF and Scharkow M (2013) The relative trustworthiness of tests of indirect effects instatistical mediation analysis. Does method really matter? Psychological Science 24(10), 1918-1927.

Henseler J (2017) Bridging design and behavioral research with variance-based structural equation modeling. Journal of Advertising 46(1), 178-192.

Henseler $\mathbf{J}$ et al (2014) Common beliefs and reality about partial least squares: comments on Rönkkö \& Evermann (2013). Organizational Research Methods 17(2), 182-209.

Henseler J, Hubona G and Ray PA (2016) Using PLS path modeling in new technology research: updated guidelines. Industrial Management \& Data Systems 116(1), 2-20.

Henseler J, Ringle CM and Sarstedt M (2015) A new criterion for assessing discriminant validity in variance-based structural equation modeling. Journal of the Academy of Marketing Science 43(1), 115-135.

Huang J-W and Li Y-H (2009) The mediating effect of knowledge management on social interaction and innovation performance. International Journal of Manpower 30(3), 285-301.

Husted BW and De Jesus Salazar J (2006) Taking friedman seriously: maximizing profits and social performance. Journal of Management Studies 43(1), 75-92.

Inkinen H (2016) Review of empirical research on knowledge management practices and firm performance. Journal of Knowledge Management 20(2), 230-257.

Jansen JJP, Van den Bosch FAJ and Volberda HW (2005) Managing potential and realized absorptive capacity: how do organizational antecedents matter? Academy of Management Journal 48(6), 999-1015. 
Kransdorff A and Williams R (2000) Managing organizational memory (OM): the new competitive imperative. Organization Development Journal 18(1), 107-117.

Kurland N and Pelled L (2000) Passing the word: toward a model of gossip and power in the workplace. Academy of Management Review 25(2), 428-438.

Lane PJ, Koka BR and Pathak S (2006) The reification of absorptive capacity: a critical review and rejuvenation of the construct. Academy of Management Review 31(4), 833-863.

Lee V, Leong L, Hew T and Ooi K (2013) Knowledge management: a key determinant in advancing technological innovation? Journal of Knowledge Management 17(6), 848-872.

Liao S, Chang J, Cheng S and Kuo C (2004) Employee relationship and knowledge sharing: a case study of a Taiwanese finance and securities firm. Knowledge Management Research \& Practice 2(1), 24-34.

Liao S-H, Wu C-C, Hu D-C and Tsui K-A (2010) Relationships between knowledge acquisition, absorptive capacity and innovation capability: an empirical study on Taiwan's financial and manufacturing industries. Journal of Information Science 36(1), 19-35.

Lin H-F (2007) A stage model of knowledge management: an empirical investigation of process and effectiveness. Journal of Information Science 33(6), 643-659.

Martelo-Landroguez S and Cegarra JG (2014) Linking knowledge corridors to customer value through knowledge processes. Journal of Knowledge Management 18(2), 342365.

Martelo-Landroguez S and Cepeda G (2016) How knowledge management processes can create and capture value for firms? Knowledge Management Research \& Practice 14(4), 423-433.

Martelo-Landroguez S and Martin-Ruiz D (2016) Managing knowledge to create customer service value. Journal of Service Theory and Practice 26(4), 471-496.

Moorman C and Miner AS (1998) Organizational improvisation and organizational memory. Academy of Management Review 23(4), 698-723. 
Moustaghfir K (2009) How knowledge assets lead to a sustainable competitive advantage: are organizational capabilities a missing link? Knowledge Management Research \& Practice 7(4), 339-355.

Newey LR and Zahra SA (2009) The evolving firm: how dynamic and operating capabilities interact to enable entrepreneurship. British Journal of Management 20, S81-S100.

Nilakanta S, Miller LL and Zhu D (2006) Organizational memory management: technological and research issues. Journal of Database Management 17(1), 85-94.

Nunnally JC (1978) Psychometric Theory. McGraw-Hill, New York, NY.

Quinn RE and Rohrbaugh J (1983) A spatial model of effectiveness criteria: towards a competing values approach to organizational analysis. Management Science 29(3), 363-377.

Richter NF, Cepeda G, Roldan JL and Ringle CM (2016) European management research using partial least squares structural equation modeling (PLS-SEM). European Management Journal 34(6), 589-597.

Rigdon EE (2016) Choosing PLS path modeling as analytical method in European management research: a realist perspective. European Management Journal 34(6), 598-605.

Ringle CM, Wende S and Becker JM (2015) SmartPLS 3. Boenningstedt: SmartPLS GmbH, http://www.smartpls.com.

Ronstadt R (1988) The corridor principle. Journal of Business Venturing 3(1), 31-40.

Sánchez-Casado N, Cegarra JG and Tomaseti-Solano E (2015) Linking social networks to utilitarian benefits through counter-knowledge. Online Information Review 39(2), 179-196.

Schaefer R (2005) Sociology: A Brief Introduction. Princeton, N.J.

Schiuma G (2009) The managerial foundations of knowledge assets dynamics. Knowledge Management Research \& Practice 7(4), 290-299. 
Schiuma G (2012) Managing knowledge for business performance improvement. Journal of Knowledge Management 16(4), 515-522.

Stein EW (1995) Organization memory: review of concepts and recommendations for management. International Journal of Information Management 15(1), 17-32.

Thompson D (2008) Counter-knowledge. Atlantic Books, London.

Venkatraman N and Ramanujam V (1987) Measurement of business economic performance: an examination of method convergence. Journal of Management 13(1), 109-122.

Walsh JP and Ungson GR (1991) Organizational memory. Academy of Management Review 16(1), 57-91.

Wee JCN and Chua AYK (2013) The peculiarities of knowledge management processes in SMEs: the case of Singapore. Journal of Knowledge Management 17(6), 958972.

Yerkovich S (1977) Gossiping as a way of speaking. Journal of Communication 27(1), 192-196. 
Table 1: Reliability, convergent validity, and discriminant validity values of outer model

\begin{tabular}{|c|c|c|c|c|c|c|c|c|}
\hline & & & & \multicolumn{5}{|c|}{ HTMT } \\
\hline Construct & $\begin{array}{c}\text { rho_A } \\
(\rho)\end{array}$ & $\begin{array}{l}\text { Composite } \\
\text { reliability }\end{array}$ & AVE & (RACAP) & $(\mathrm{CK})$ & $(\mathrm{OM})$ & $(\mathrm{KA})$ & $(\mathrm{P})$ \\
\hline $\begin{array}{r}\text { Realized Absorptive Capacity } \\
\text { (RACAP) }\end{array}$ & 0.870 & 0,870 & 0,885 & & & & & \\
\hline Counter-knowledge (CK) & 0.986 & 0.952 & 0.831 & 0.179 & & & & \\
\hline Organizational memory (OM) & 0.941 & 0.922 & 0.748 & 0.634 & 0.114 & & & \\
\hline Knowledge application (KA) & 0.967 & 0.970 & 0.764 & 0.849 & 0.199 & 0.676 & & \\
\hline Performance (P) & 0.964 & 0.969 & 0.722 & 0.759 & 0.126 & 0.683 & 0.126 & \\
\hline
\end{tabular}


Table 2. Construct effects on endogenous variables (incl. lower and upper bounds of $95 \%$ confidence interval)

\begin{tabular}{lcccc}
\hline \multicolumn{1}{c}{ Hypotheses } & Path Coef. & \multicolumn{2}{c}{ Confidence intervals } & Supported \\
\hline & & $95 \% \mathrm{Cl}_{\mathrm{li}}$ & $95 \% \mathrm{Cl}_{\mathrm{hi}}$ & \\
\hline H1: RACAP $\rightarrow$ OM & 0.594 & 0.509 & 0.685 & Yes \\
H2: OM $\rightarrow$ KA & 0.650 & 0.567 & 0.738 & Yes \\
H3: KA $\rightarrow$ Performance & 0.809 & 0.758 & 0.859 & Yes \\
H4: CK $\rightarrow$ RACAP & -0.170 & -0.320 & -0.043 & Yes \\
H5:CK $\rightarrow$ OM & -0.017 & -0.127 & 0.094 & No \\
H6: CK $\rightarrow$ KA & -0.121 & -0.227 & -0.022 & Yes \\
H7: CK $\rightarrow$ Performance & 0.034 & -0.043 & 0.112 & No \\
\hline
\end{tabular}

Note: one-tailed test was used by testing hypotheses through percentile confidence intervals 
Figure 1. Proposed Research Model

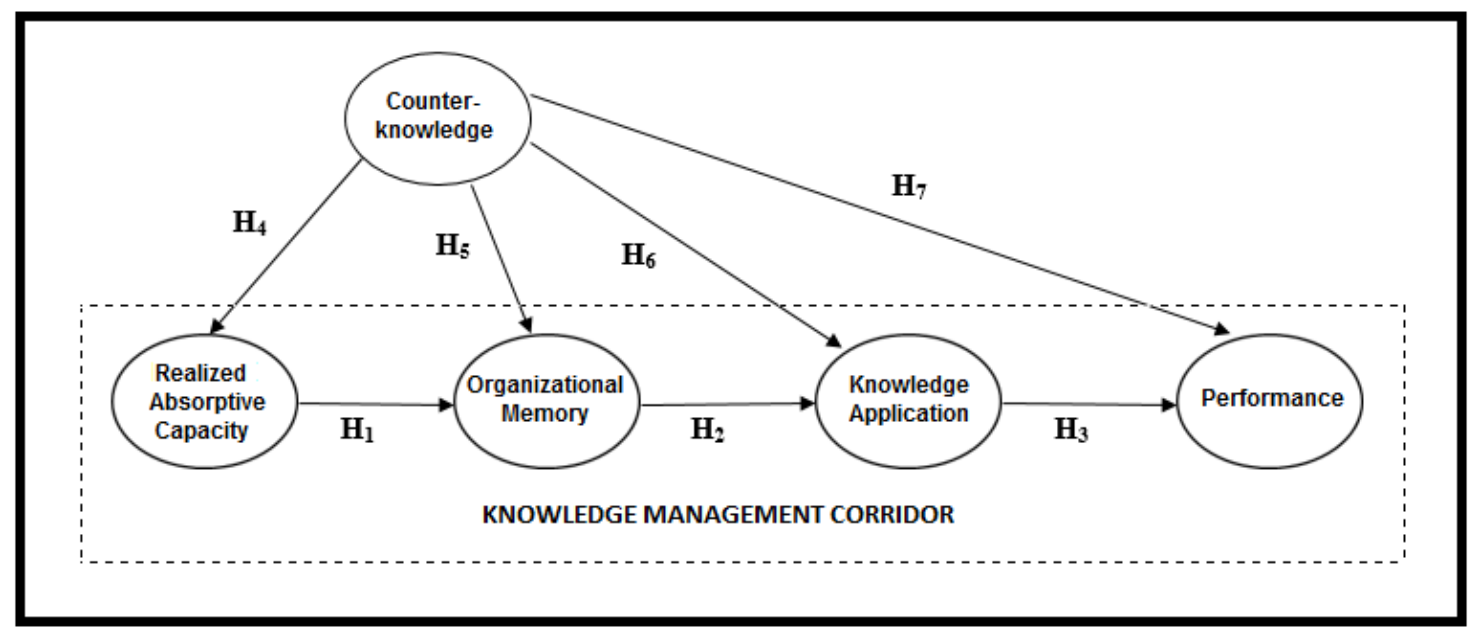

